\title{
The magma source of small-scale monogenetic volcanic systems.
}

\author{
IAN E M SMITH ${ }^{1 *}$, SHANE J CRONIN ${ }^{1}$, LUCY E MCGEE ${ }^{2}$, \\ MARCO BRENNA ${ }^{3}$
}

${ }^{1}$ School of Environment, University of Auckland, Auckland, New Zealand (correspondence: ie.smith@auckland.ac.nz) ${ }^{2}$ Department of Geology, University of Adelaide, Adelaide, Australia

${ }^{3}$ Department of Geology, Otago University, Dunedin, New Zealand

Small-scale basaltic magmatic systems are expressed as fields of monogenetic volcanoes at the Earth's surface. Commonly but not exclusively magma compositions reflect processes at or near mantle source depths and crystal zoning patterns reveal rapid ascent rates. A significant question is that of how mantle sources yield very small volume magma batches over time scales of $10^{6}-10^{7}$ years.

The Auckland intraplate volcanic province of northern New Zealand consists of four small fields of monogenetic volcanoes. Each of these was active for a period of $\sim 1 \mathrm{ma}$ and the locus of activity migrated northward in discrete $\sim 50 \mathrm{~km}$ steps during the last $3 \mathrm{ma}$. The most recent of these fields is the Auckland Volcanic Field (AVF) and it provides a key to understanding the source processes that yield monogenetic volcano fields. In the AVF individual eruptive events have produced compositionally distinct basalt magma within the range nephelinite to tholeiite. Eruptions have been irregularly spaced during the $200 \mathrm{kyr}$ life of the field with repose periods of $\leq 0.1$ to $13 \mathrm{kyr}$. A significant flare-up in activity at about $30 \mathrm{kyr}$ produced compositionally discrete events from spatially separate locations within a temporal interval of as little as 100 years. An interpretation of these data is that each of these events represents a discrete batch of magma extracted from a preexisting asthenospheric mantle cystal-liquid mush. We postulate that such a mush forms when upwelling mantle undergoes adiabatic partial melting and that it can exist as a metastable entity at the asthenosphere-lithosphere boundary for proponged periods $\left(10^{5}-10^{6}\right.$ years $)$ during which time it can be tapped to create individual magma batches. The range of compositions observed in the AVF are explained by variable melt/solid ratios and modal heterogeneity in the mantle mush.

In northern New Zealand formation of four spatially separate monogenetic systems at intervals of $\sim 10^{6}$ years is linked to the long term tectonics of the Pacific-Australian Plate boundary beneath the New Zealand region. The shorter term magma extraction events that produced the individual volcanoes are the result of crustal scale tectonic events. 